\title{
Study of synthesis parameters and active layer morphology of interfacially polymerized polyamide-polysulfone membranes
}

\author{
Sanne Hermans ${ }^{\mathrm{a}}$, Roy Bernstein ${ }^{\mathrm{a}}$, Alexander Volodin ${ }^{\mathrm{b}}$, Ivo F.J. Vankelecom ${ }^{\mathrm{a}, *}$ \\ ${ }^{\text {a }}$ Centre for Surface Chemistry and Catalysis, Department of Molecular and Microbial Systems, KU \\ Leuven, Kasteelpark Arenberg 23, PO Box 2461, 3001 Leuven, Belgium \\ b Laboratory of Solid-State Physics and Magnetism, Department of Physics and Astronomy, KU \\ Leuven, Celestijnenlaan 200d, 3001 Leuven, Belgium \\ * Corresponding author: ivo.vankelecom@biw.kuleuven.be, tel: +3216321594
}

\begin{abstract}
Thin film composite (TFC) polyamide membranes were prepared on a polysulfone support membrane and the effect of various synthesis conditions on the active layer morphology, the physicochemical properties and the membrane performance was investigated. The support membrane porosity factor had a significant effect on the TFC membrane performance. A polyamide top layer was formed within $15 \mathrm{~s}$ of reaction. Prolonging the reaction time, although resulting in a thicker active layer, only had a minor influence on the membrane performance. This highlights the importance of the incipient layer of the polyamide structure on its performance. The addition of both a surfactant and a base to the amine solution resulted in a change of the active layer morphology and an improved performance. The effect of additives was attributed to changes in the polymerization mechanism. In addition, it was demonstrated that curing at $50^{\circ} \mathrm{C}$ resulted in an improved membrane performance, due to more cross-linking of the active layer. Curing at higher temperatures deteriorated the structure of the support membrane. This research shows that the TFC membrane performance is well correlated with the changes in the active layer morphology, measured using SEM, AFM and TEM; whereas only minor changes in the physicochemical characteristics of the membranes were detected by zeta potential and ATR-FTIR spectroscopy when the same synthesis parameters were varied.
\end{abstract}

\section{KEY WORDS}

Thin film composite membranes; Interfacial polymerization; Aromatic polyamide; Synthesis parameters; Morphology 


\section{Introduction}

Thin film composite (TFC) membranes with polyamide (PA) as an active layer synthesized via interfacial polymerization (IP) are dominant in aqueous nanofiltration (NF) and 'reverse osmosis' (RO). These composite membranes comprise three distinct layers: a non-woven fabric which provides mechanical support, a porous support layer (usually poly(ether)sulfone, 30 to 50 micron thick), and the PA active layer, synthesized using IP, on the porous support. In order to fabricate the TFC PA membrane, the porous support layer is impregnated with an aqueous amine solution, and subsequently put into contact with an immiscible organic solvent that contains acyl chloride as the second monomer. The monomers react at the interface between the two solvents, slightly more towards the organic phase, to form a very thin PA layer of a few tens to hundreds nanometer in thickness [1]. This resulting thin layer is a very dense film, which is characterized by a high abundance of hydrogen bonds and a controllable degree of cross-linking via addition of multifunctional monomers, making these membranes superior for aqueous applications, especially for salt rejection.

Extensive research on different aspects of fabricating PA via IP for membrane synthesis was conducted since it was first presented by Cadotte [2]. These studies focused mainly on the polymerization between m-phenylenediamine (MPD) or piperazine (PIP) as the amine monomers and trimesoyl chloride (TMC) as the acyl chloride monomer. In addition, many studies explored the use of other monomers besides these commonly used. Furthermore, the synthesis of polymeric top layers other than PA via IP has been investigated, for example: polyurea, poly(urea amide), poly(amide imide) and poly(ether amide) TFC membranes. A comprehensive review regarding the different polymers as well as other monomers for PA synthesis can be found in Petersen [1], Lee et al. [3] and Lau et al.[4].

However, it seems that PA synthesized using MPD or PIP with TMC has a favorable combination of properties for desalination, i.e. high salt removal as well as high permeability, robustness and durability. As a consequence, many researchers investigated the polymerization mechanism, kinetics and the optimization of the synthesis conditions of this system. This includes the addition of additives [5-11], optimizing reaction temperature [12, 13], membrane curing time [14-16], the effect of the support membrane [16-19], etc. It is believed that a small change in the membrane properties (e.g. hydrophilicity, thickness) might result in a significant improvement in the overall performance. Moreover, because physicochemical membrane characteristics govern the propensity to (bio)fouling and scaling, it is also important to understand the effect of the various synthesis parameters on these properties [18, 20,21]. Although PA membranes are well known for aqueous applications, the composition and production process is often proprietary.

The aim of this research is to add information on the correlation between the polymerization conditions, membrane performance and the active layer characterization. This will lead to better understanding on PA film formation and TFC membrane design. A systematic parameter study was done on the effects of the support membrane, additives, reaction time and curing on the PA membrane performance and morphology. The influence of these parameters on membrane performance was thoroughly investigated using a high throughput 
filtration module $[22,23]$. The results are discussed based on the accepted IP mechanism [2426] and verified by a systematic characterization using SEM, AFM and TEM.

\section{Material and Methods}

\subsection{Material}

Polysulfone (PSf, Mn 22000) was purchased from Sigma-Aldrich. The non-woven polypropylene/polyethylene (PP/PE) fabric Novatexx 2471 was kindly provided by Freudenberg (Germany). Trimesoylchloride (TMC, Acros), meta-phenylenediamine (MPD, Acros), triethylamine (TEA, Sigma-Aldrich), sodium hydroxide $(\mathrm{NaOH}$, Fisher) and sodium dodecyl sulfate (SDS, Acros) were used for IP. N-methylpyrrolidone (NMP, VWR) and hexane (VWR) were used as received. Magnesium sulfate $\left(\mathrm{MgSO}_{4}\right.$, Sigma-Aldrich) was applied as test solute. All experiments were done with purified water from a Milli-Q system (Millipore).

\subsection{Membrane Synthesis}

\subsubsection{PSf support}

PSf ultrafiltration membranes were synthesized via phase-inversion. Homogeneous solutions of PSf (dried overnight at $110^{\circ} \mathrm{C}$ ) in NMP were cast on a PP/PE non-woven. Casting solutions were prepared using 14, 16, 18, 20, 22 and 24 wt\% PSf. The non-woven was first impregnated with NMP, to prevent intrusion of the casting solution in its porous structure. This was done by uniformly spraying NMP over the non-woven until all pores were saturated, and then quickly wiping excess solution of the surface with paper. Films were cast at constant speed $(77 \mathrm{~mm} / \mathrm{s})$ with an automatic casting device (Braive Instruments, Belgium) at $200 \mu \mathrm{m}$ wet thickness. The polymer films were then immersed in distilled water (room temperature) for $30 \mathrm{~min}$. Hereafter, they were rinsed for $10 \mathrm{~min}$ and stored in distilled water until further use. The humidity and temperature during casting were not externally controlled but varied in the range of $42-48 \%$ and $17-21^{\circ} \mathrm{C}$, respectively.

\subsubsection{Thin film composite}

A thin PA layer was synthesized on top of the PSf support via IP. A support layer was impregnated for $30 \mathrm{~min}$ with a solution of $2 \% \mathrm{MPD}(\mathrm{w} / \mathrm{v}), 2 \%$ TEA (w/v) and $0.1 \%$ SDS (w/v) in water (unless specified otherwise). Then, the excess aqueous solution was removed from the PSf membrane using a rubbery wiper. After $1 \mathrm{~min}$, a solution of $0.1 \%(\mathrm{w} / \mathrm{v}) \mathrm{TMC}$ in hexane was subsequently poured gently on the impregnated support layer. The hexane solution was drained off after 1 min of polymerization (unless specified otherwise) and the synthesized TFC membranes were stored at room temperature to dry overnight. Post treatment was done by placing the membranes for $10 \mathrm{~min}$ in an oven at $50^{\circ} \mathrm{C}$ (unless specified otherwise). Finally, the membranes were stored in distilled water and in the dark. 


\subsection{Membrane characterization}

\subsubsection{Filtration experiments}

The filtration experiments were done with a high throughput filtration module which allowed 16 simultaneous dead-end filtrations (active area of each membrane $1.77 \mathrm{~cm}^{-2}$ ) under the exact same operating conditions [22, 27]. The feeds were rigorously stirred at $500 \mathrm{rpm}$ to minimize concentration polarization. The membrane performance was tested with a $1 \mathrm{~g} / \mathrm{L}$ $\mathrm{MgSO}_{4}$ solution in Milli-Q water. Every membrane was tested three times.

Membrane permeance $\left(\mathrm{L}_{\mathrm{p}}\right)$ was calculated using:

$$
L_{p}=\frac{V}{A \cdot t \cdot \Delta P}
$$

where, $\mathrm{V}$ is the feed volume (L) that passed through the membrane, $\mathrm{A}$ is the membrane area $\left(\mathrm{m}^{2}\right), \mathrm{t}$ is the time $(\mathrm{h})$ and $\Delta \mathrm{P}$ is the applied pressure (bar).

The rejection was calculated using:

$$
R=\frac{\Lambda_{r}-\Lambda_{p}}{\Lambda_{r}} \times 100
$$

in which $\Lambda_{\mathrm{r}}$ and $\Lambda_{\mathrm{p}}$ are the retentate and the permeate conductivity (K620 Consort, Belgium), respectively.

A "porosity factor" $\varepsilon \cdot r_{p}^{2}$ was defined for the PSf support membranes based on the HagenPoiseuille pore flow model:

$$
L_{p}=\frac{s r_{p}^{2}}{8 \mu \delta_{m}}
$$

where $\mathrm{L}_{\mathrm{p}}$ is the membrane permeance $\left(\mathrm{m}^{2} /(\mathrm{m} \cdot \mathrm{Pa} \cdot \mathrm{s})\right), \varepsilon$ is the membrane porosity, $\mathrm{r}_{\mathrm{p}}$ is the pore radius $(\mathrm{m}), \mu$ is the solution viscosity $\left(0.001 \mathrm{~Pa} \cdot \mathrm{s}\right.$ for water at room temperature), and $\delta_{\mathrm{m}}$ is the membrane thickness $(\mathrm{m})$, estimated from SEM images. Including both porosity and pore radius, this factor represents the overall effect of the pores (and not one specific characteristic). An increase can indicate a higher porosity, higher pore radius or both.

\subsubsection{Electron Microscopy}

The cross-section morphology was analyzed with scanning electron microscopy (SEM), Philips XL 30 FEG SEM. Samples were broken in liquid nitrogen and coated with a thin (1.5 - $2 \mathrm{~nm}$ ) gold layer using a Cressington HR208 high resolution sputter coater. Transmission electron microscopy (TEM) was applied for top layer visualization at higher resolution. Unstained membrane samples were embedded in an araldite resin (Polyscience) and cut into ultrathin $(70 \mathrm{~nm})$ cross-sections with a Reichert Ultracut E microtome. Images were taken with a Zeiss EM900 TEM. Top layer thickness was calculated as the average of 11 equidistant spots along the entire cross-section.

\subsubsection{Atomic Force Microscopy (AFM)}

Membrane topographic images were acquired under water (TM Direct Drive holder) using a Dimension 3100 device (Bruker) in tapping mode with standard NC cantilevers (Nanosensors, PPP-NCHR, resonant frequency in air $\sim 320 \mathrm{kHz}$ ). Each sample was measured 
over an area of $5 \mu \mathrm{m}^{2}$. The reported RMS roughness is the average of at least three different locations on each sample.

\subsubsection{Attenuated Total Reflectance Infra-Red (ATR-IR) Spectroscopy}

ATR-FTIR spectra were collected from dried membranes using a Bruker ALPHA-P FTIR spectrometer with a diamond ATR crystal. Forty scans were collected at a resolution of $4 \mathrm{~cm}^{-}$

${ }^{1}$. For every membrane at least three different positions were measured.

\subsubsection{Zeta potential}

Zeta potential measurements were performed using a SurPASS streaming potential analyzer (Anton Paar GmbH, Graz, Austria) with an adjustable gap cell. The background solution was $1 \mathrm{mM} \mathrm{KCl}$ and the $\mathrm{pH}$ was adjusted using $\mathrm{HCl}(0.1 \mathrm{M})$ and $\mathrm{NaOH}(0.1 \mathrm{M})$. The zeta potential was determined using the Fairbrother-Mastin equation.

\section{Results and discussion}

\subsection{Characterization of the support membrane}

Figure 1 presents the water permeance and the corresponding porosity factors (equation 3) of the uncoated PSf support membranes that were prepared using different PSf concentrations $(\mathrm{wt} \%)$ in the casting solution.

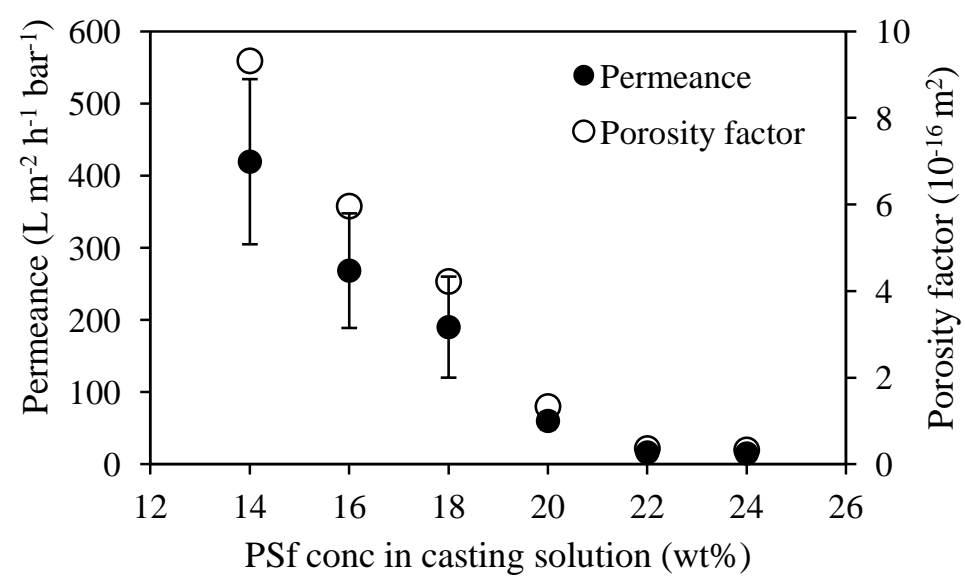

Figure 1: Water permeance of PSf supports synthesized from casting solutions with varying PSf concentration. Filtrations carried out at 1 bar (except 22 and $24 \mathrm{wt} \%$ at 2 bar, due to slow permeation).

As expected, increasing the polymer concentration in the casting solution leads to both a decrease in permeance [27-29] and in the porosity factor.

From Figure 1 it seems that two types of ultrafiltration (UF) membranes are obtained, depending on the PSf concentration: membranes with high porosity and flux (14 to 20\%), which can be characterized as 'loose' UF membranes, and membranes with low porosity and flux (22 and $24 \%$ ), that can be considered as 'tight' UF membranes. It is noted that the permeance of the tight UF membranes is already similar to that of NF membranes $\left(15 \mathrm{~L} \mathrm{~m}^{-2}\right.$ $\left.\mathrm{h}^{-1} \mathrm{bar}^{-1}\right)$. 
(a)

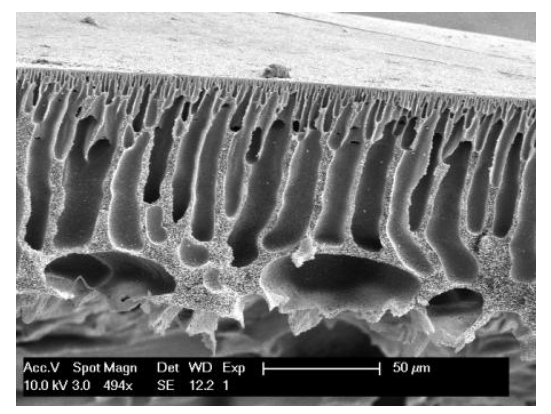

(c)

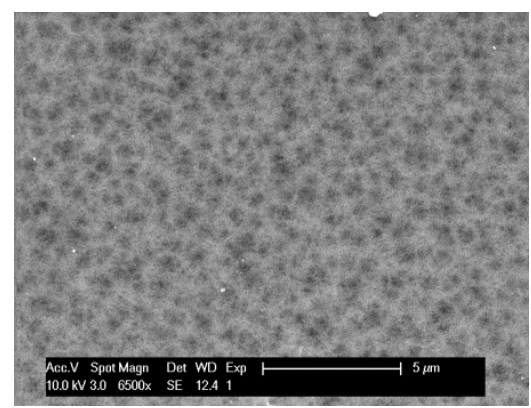

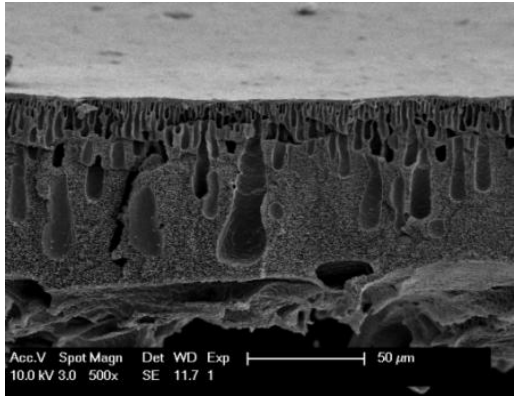

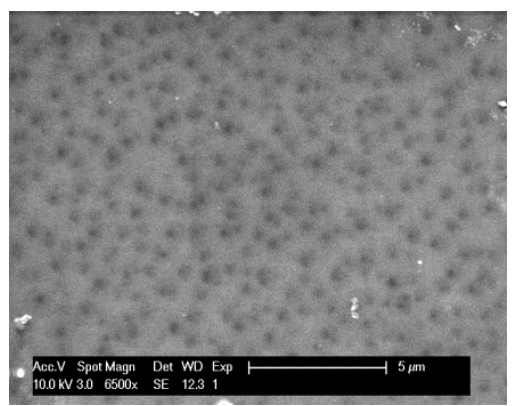

(b)

(d)

Figure 2: Typical cross-section SEM images of PSf supports synthesized from casting solutions with (a) $18 \mathrm{wt} \%$ and (b) 22 wt $\%$ PSf. Surface SEM images of PSf supports synthesized from casting solutions with (c) $14 \mathrm{wt} \%$ and (d) $18 \mathrm{wt} \%$ PSf.

Cross-section SEM images of membranes prepared with 18 and 22\% PSf (Figure 2a and 2b) show the different morphologies of the loose and tight UF membranes. The loose UF membrane consists of fingerlike macrovoids throughout the entire cross-section, while the more tight UF membrane clearly shows less macrovoids, which do not cross the entire membrane thickness. Surface SEM images (Figure 2c and 2d) confirm the decreasing porosity with increasing polymer concentration (i.e. decreasing porosity factor).

It should be noted that using the PSf concentration in the casting solution as a standard synthesis parameter can be problematic, since membranes synthesized with the same PSf concentration in the casting solution can have a different structure and performance depending on the casting conditions (e.g. humidity, temperature, molecular weight of the PSf) [30]. Therefore, we suggest the use of support porosity factor as a more general term to describe the supports.

\subsection{Effect of support porosity on the TFC performance}

PA membranes were synthesized on the various PSf supports (at otherwise constant conditions). The reaction scheme is given in Supplementary Information (SI), together with ATR-FTIR spectra which confirm the successful polymerization. The ATR-FTIR spectra for the membranes that were synthesized on the different PSf supports were similar (Figure $\mathrm{C}$ in SI). Thus, it can be assumed that the porosity factor of the support membrane has little - if any - influence on the chemical composition of the reaction product from the two monomers.

Figure 3 presents the performance of the PA TFC membranes synthesized on the supports prepared using the different PSf concentrations (see 3.1), at otherwise constant conditions. These membranes will be referred to as TFC-PSfx with $\mathrm{x}$ being the \%PSf concentration applied to synthesize the support. 
(a)

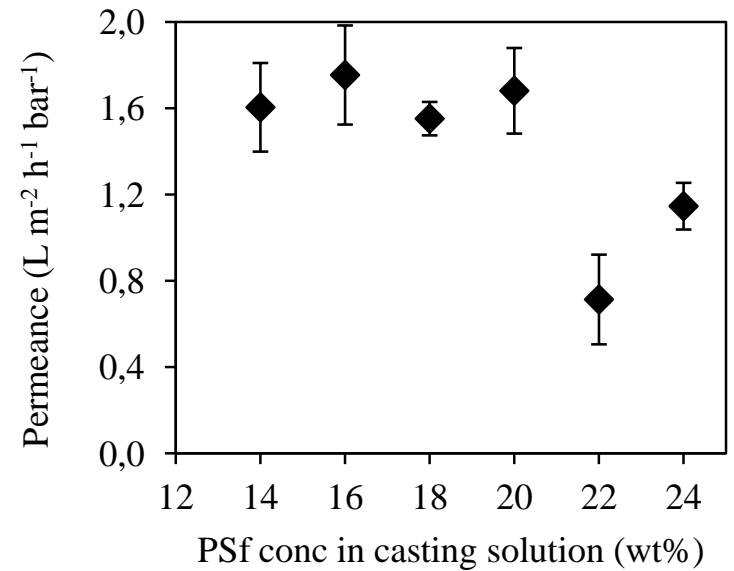

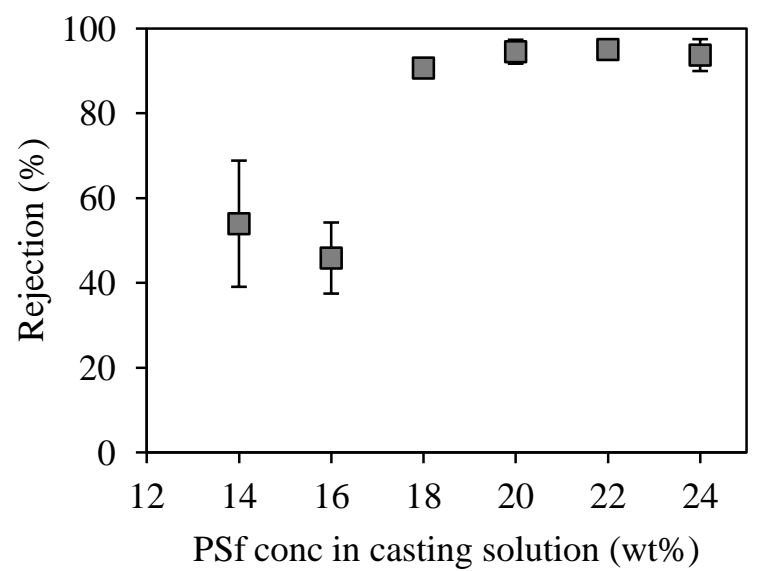

(b)

Figure 3: Water permeance (a) and salt rejection (b) of TFC membranes synthesized from casting solutions with varying PSf concentration. Synthesis conditions: MPD, TEA and SDS present in the aqueous solution, $60 \mathrm{~s}$ reaction time and curing at $50^{\circ} \mathrm{C}$ for $10 \mathrm{~min}$. Filtration conditions: $25 \mathrm{bar}, 1 \mathrm{~g} / \mathrm{L} \mathrm{MgSO}$.

The water permeance of the TFC-PSf14 to TFC-PSf20 membranes was similar and decreased for TFC-PSf22 and TFC-PSf24, as was also found by others [16, 19]. On the other hand, TFC-PSf14 and TFC-PSf16, with supports characterized by high porosity factors (Figure 1), resulted in lower salt rejection (Figure 3a). Therefore, it is suggested that there is a limited range for the porosity factor of the support membrane, from which a TFC membrane with high performance can be obtained. This is in line with the findings of Petersen [1] who stated that there is an upper limit pore size for a support layer of approximately $100 \mathrm{~nm}$, i.e. UF supports are needed for the preparation of a defect-free TFC membrane with high performance. Based on these experiments, the optimal porosity factor for a support membrane to be used for IP is approximately $1.3 \cdot 10^{-16} \mathrm{~m}^{2}$, which corresponds to $20 \mathrm{wt} \%$ PSf in the casting solution in this set of experiments.

The lower permeance of the TFCs comprising supports with low porosity factors, is probably due to the mass transfer resistance of the support membranes. When the support membrane is a loose UF membrane (Figure 1) the permeance of the TFC membrane is mainly determined by the intrinsic permeance of the PA layer, whereas when the support membrane is a tight UF membrane, its intrinsic permeance is already low, resulting in a much lower permeance of the TFC membrane. Moreover, when the support porosity is high, as for 14 and 16\% PSf, the PA cannot form well at the support surface and chances for defects increase, thus leading to a low salt rejection [17].

\subsection{Reaction time}

The influence of the reaction time between MPD and TMC (with additives in the aqueous solution) on the membrane performance is presented in Figure 4. 


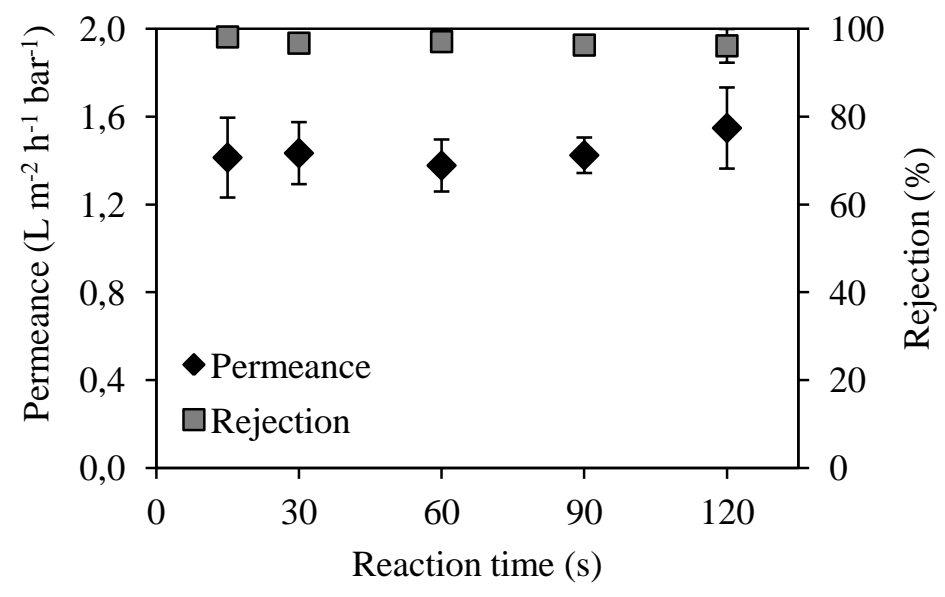

Figure 4: Water permeance and salt rejection of TFC membranes synthesized with different reaction times. Synthesis conditions: MPD, TEA and SDS present in the aqueous solution, $18 \%$ PSf in casting solution of the support and curing at $50^{\circ} \mathrm{C}$ for $10 \mathrm{~min}$. Filtration conditions: $36 \mathrm{bar}, 1 \mathrm{~g} / \mathrm{L} \mathrm{MgSO}_{4}$.

The permeance and salt rejection, shown in Figure 4, indicate that prolonging the reaction time to more than $15 \mathrm{~s}$ has no significant influence on the membrane performance. It can thus be concluded that the PA layer is already completely formed within $15 \mathrm{~s}$ of contact between the two phases. Shorter reaction times were not tested due to technical limitations during labscale membrane synthesis.

It is generally accepted that longer reaction times result in a thicker top layer and, hence, a decrease in flux. However, the polymerization reaction quickly starts slowing down significantly due to limited diffusion of the amine monomer through the formed PA barrier towards the organic phase $[10,31]$. Furthermore, the PA layer is composed of two layers: an initially formed dense and highly cross-linked base layer (incipient layer), and a more loose PA on top, causing the ridge and valley morphology but having less effect on the actual membrane performance $[12,26]$. It is noted that the relatively constant permeance in this experiment was somewhat unexpected, since it is generally accepted that permeance is inversely proportional to membrane thickness [32]. This, however, highlights the importance of the PA incipient layer, which seems to remain rate-limiting, on the membrane performance, in agreement with others [12].

In this experiment, a TFC membrane was formed within $15 \mathrm{~s}$ (based on performance). Therefore, it can be estimated that after $15 \mathrm{~s}$, the diffusion limited growth stage was reached in this self-inhibiting process [26], and that prolonging the reaction time mainly increased the thickness of the loose ridge and valley structure of the active layer [9, 33]. This was seen using electron microscopy. Figure 5 presents the TEM and SEM images of PA membranes, obtained after different reaction times. Due to the ridge and valley morphology, the average thickness of the top layers evaluated from the TEM images has a high standard deviation. Still, it is clear that after $15 \mathrm{~s}$ reaction time, the average PA thickness $(178 \pm 69 \mathrm{~nm})$ was lower than after a $120 \mathrm{~s}$ reaction time $(300 \pm 141 \mathrm{~nm})$. Yet, as aforementioned, the PA thickness did not alter the membrane performance significantly (Figure 4). The more pronounced ridge and valley morphology at higher reaction times can be clearly seen in the 
SEM surface images of TFC membranes synthesized at $15 \mathrm{~s}$ and $120 \mathrm{~s}$ (Figure $5 \mathrm{~b}$ and 5d), as well as in the TEM cross-section images for these two membranes (Figure 5a and 5c).

(a)

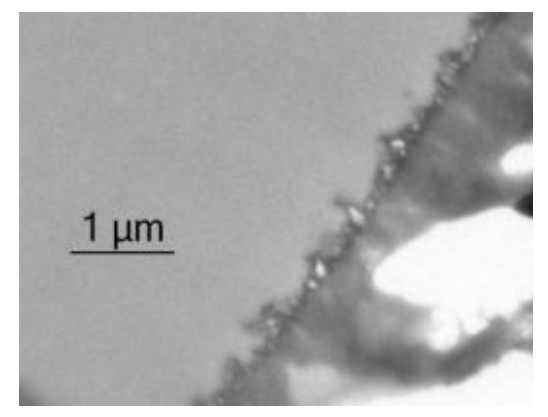

(c)

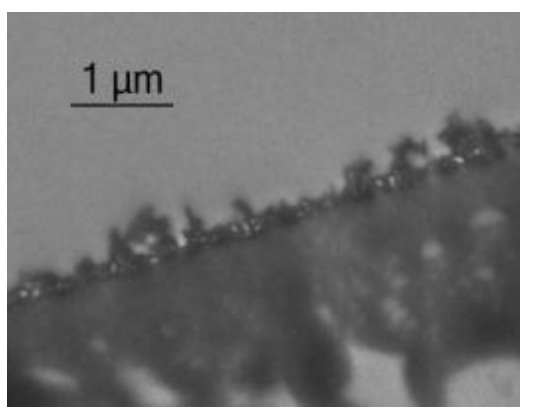

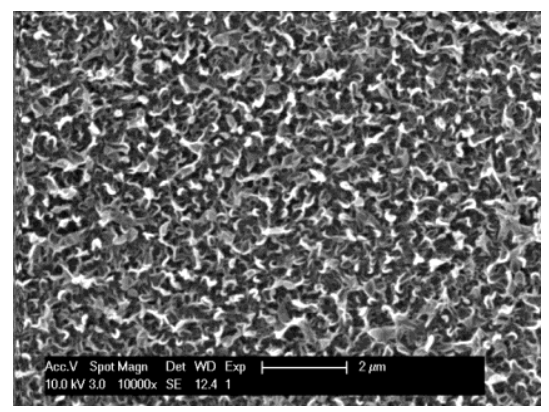

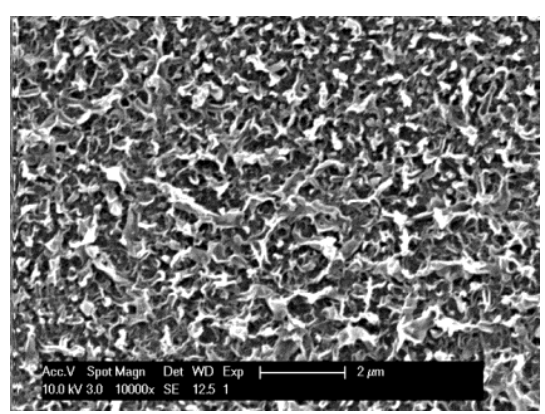

(b)

(d)

Figure 5: TEM cross-section (left) and SEM surface images (right) of TFC membranes with a reaction time of $15 \mathrm{~s}(\mathrm{a}, \mathrm{b})$ and $120 \mathrm{~s}(\mathrm{c}, \mathrm{d})$.

Since TEA was added to the aqueous phase in order to catalyze the polymerization reaction, as will be discussed in the following section, the influence of the reaction time might be better observable without the addition of TEA. Nevertheless, the performance of two TFC membranes that were synthesized without TEA (i.e. only MPD and SDS in the aqueous phase) at $15 \mathrm{~s}$ and $120 \mathrm{~s}$ reaction time was again very similar (Figure D in SI), indicating that even without the presence of a catalyst, a reaction time of $15 \mathrm{~s}$ is sufficient to obtain a well performing top layer.

\subsection{Additives}

Adding different components to the aqueous phase has been reported to influence the PA structure [6-9, 11]. Figure 6 presents the effect of additives on the TFC membrane performance. The MPD and surfactant concentration was $2 \%$ and $0.1 \%(\mathrm{w} / \mathrm{v})$, respectively. The base concentrations were equimolar: $2 \%$ TEA or $0.8 \%(\mathrm{w} / \mathrm{v}) \mathrm{NaOH}$.

The membrane which was synthesized without additives (membrane I in Figure 6) seems to have a poor performance. 


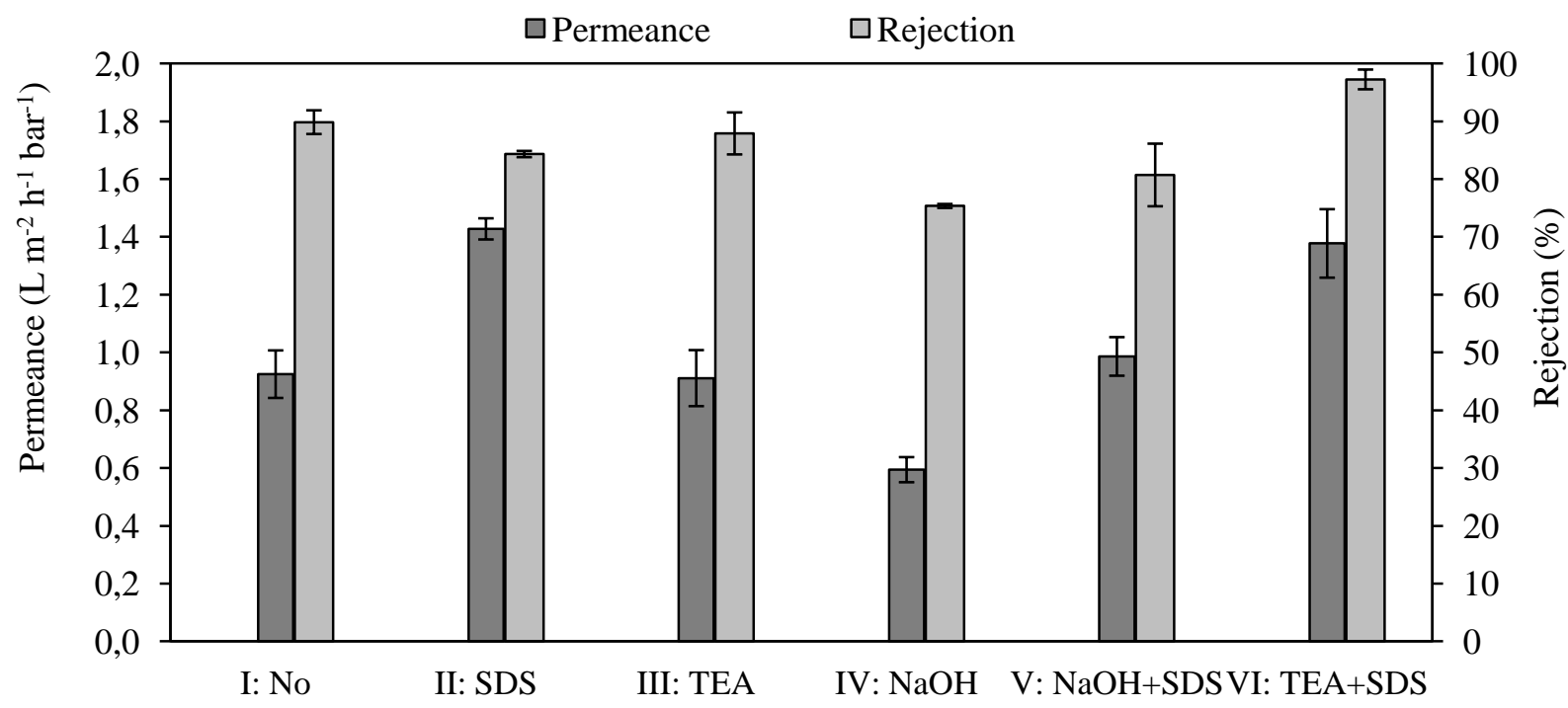

Figure 6: Water permeance and salt rejection of TFC membranes synthesized with various additives in the aqueous phase (containing MPD). Synthesis conditions: Reaction time of $60 \mathrm{~s}, 18 \%$ PSf in casting solution of the support and curing at $50^{\circ} \mathrm{C}$ for $10 \mathrm{~min}$. Filtration conditions: $41 \mathrm{bar}, 1 \mathrm{~g} / \mathrm{L} \mathrm{MgSO}$.

The addition of TEA did not improve the membrane performance; whereas the addition of $\mathrm{NaOH}$ as a base resulted in a lower performance compared to the membrane which was fabricated without additives (compare membrane I to membranes III and IV in Figure 6).

The effect of the addition of a base on membrane performance is not yet fully clarified in open literature, although its role seems to be crucial for the development of advanced TFC membranes [34]. While it was initially argued by Cadotte that adding an acid acceptor in an MPD/TMC system does not provide any advantage [1], some studies showed that the presence of TEA (together with camphorsulfonic acid) can improve the membrane performance $[12,35]$. During polymerization, $\mathrm{HCl}$ is produced in the organic phase and can diffuse to the aqueous phase where it might react with the amine monomer [1]. The base acts as an acid acceptor which captures the proton from the produced $\mathrm{HCl}$. Besides being an acid acceptor, TEA can also act as a catalyst for the reaction between the acyl choride and the amine. TEA is more nucleophilic than MPD towards the carbonyl group of the acyl chloride and the formed intermediate is more reactive towards the primary amines of MPD than the original acyl chloride. Therefore, nucleophilic catalysis occurs, and acylation of MPD by TMC is faster in the presence of TEA than in its absence, similarly to the well-known function of other tertiary amines (e.g. pyridine and 4-dimethylaminopyridine) [36]. The reaction scheme is given in Figure 7. Nonetheless, in this experiment the addition of only TEA did not improve the membrane performance, in agreement with Cadotte [37]. 

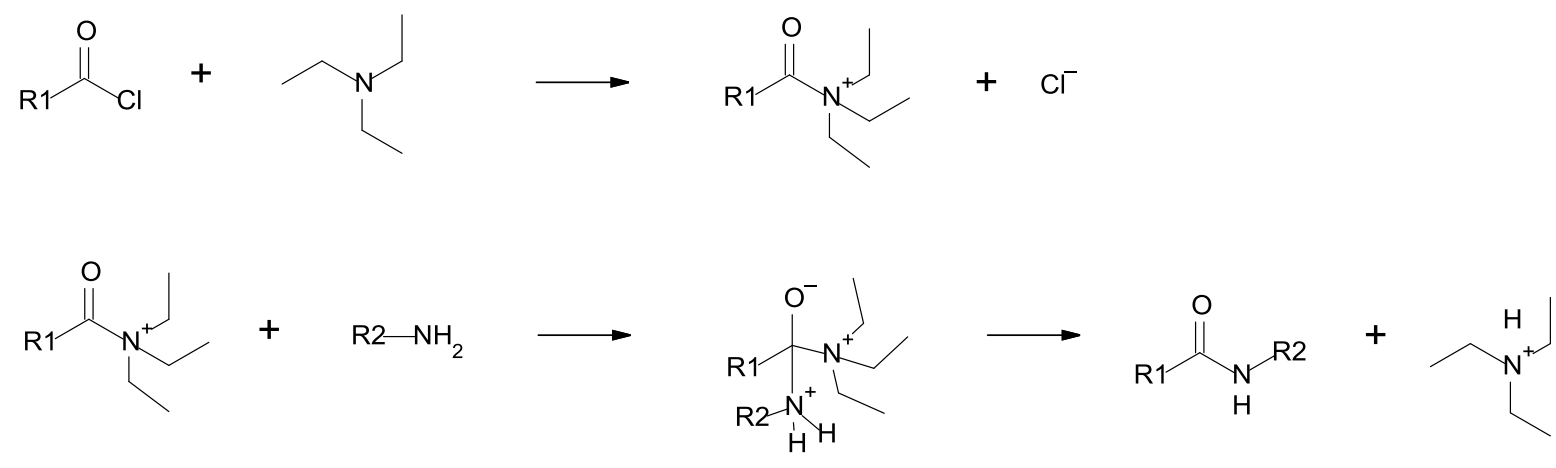

Figure 7: Scheme of the reaction between an acyl chloride and amine with TEA acting as a catalyst.

Sometimes an inorganic base, such as $\mathrm{NaOH}$, is added to the aqueous phase as acid acceptor. It is expected to be less efficient than the organic base since it will not act as a catalyst. Moreover, TEA has a higher solubility in hexane compared with $\mathrm{OH}^{-}\left(\log \mathrm{P}_{\mathrm{ow}}\right.$ of TEA is 1.45 [38]). This may allow TEA to capture protons already in the organic phase and abduct them to the aqueous phase, behaving like a phase transfer catalyst. The addition of $\mathrm{NaOH}$ in the current experiment had a negative effect and worsened the membrane performance (Figure 6, membrane IV). This, as was also suggested by Qiu et al., can be due to hydrolysis of the acyl chloride of TMC by the hydroxyl ion [5], which will lead to termination of the polymerization, a less cross-linked incipient layer and consequently a lower salt rejection. Since the salt rejection was very low after adding $\mathrm{NaOH}(75 \%)$, it can also be assumed that a defective active layer is formed. It was previously suggested that a defect-free PA layer is formed by aggregation of dense, hyperbranched PA particles [39, 40]. The addition of an inorganic base can thus influence this PA formation, resulting in defects in the active layer and consequently a lower salt rejection.

The addition of a surfactant (SDS) to the aqueous phase resulted in an elevated permeance but slightly reduced rejection (Figure 6, membrane II). However, adding SDS together with a base improved the membrane performance (Figure 6, membrane V vs. IV; and membrane VI vs. III). Surfactants are sometimes added to the aqueous phase to improve the impregnation of the rather hydrophobic PSf support with the aqueous MPD solution. Furthermore, surfactants can enhance the polymerization efficiency. Adding surfactant probably increases the amine transfer from the aqueous to the organic phase [4, 12], and consequently reduces the film thickness and increases the permeance, as was found in this experiment (compare membrane I and II in Figure 6) and by others [41]. Wittbecker and Morgan demonstrated that adding SDS is equivalent to increasing the amine concentration in the aqueous phase [42]. However, adding only SDS does not improve the rejection (compare membrane I and II, Figure 6). On the other hand, adding SDS together with a base, has a synergetic effect as evidenced by the highest performance of the membrane prepared using both additives (Figure 6, membrane VI).

Since the membrane permeance altered using the various additives, it was expected that the film thickness would follow a similar trend. However, the PA layer thicknesses of membranes with and without additives (membranes I, III and VI in Figure 6) measured using 
TEM, were not significantly different (membrane I: $143 \pm 51 \mathrm{~nm}$, membrane III: $130 \pm 46$ $\mathrm{nm}$, membrane VI: $152 \pm 53 \mathrm{~nm}$ ). This may support the assumption that the additives (added either separately or together) influence the incipient film formation or are responsible for defects in the PA layer, but do not change the overall kinetics of the film formation. The effect of the additives on the surface morphology and roughness was further studied using SEM and AFM (Figure 8 and 9).

The SEM images of the surfaces of TFC membranes synthesized with only MPD and MPD+TEA are very similar (Figure $8 \mathrm{a}$ and $8 \mathrm{~b}$ ), which is not surprisingly since they showed a similar performance. On the other hand, adding TEA+SDS clearly alters the membrane morphology, showing a different ridge and valley structure (Figure 8a and 8c). The different surface morphology is even more pronounced in the AFM images which were recorded under water, i.e. in swollen membrane state (Figure 9). Although the surface roughness of both membranes was similar ( $\mathrm{Rq} 76 \pm 8 \mathrm{~nm}$ ), a clear difference in the size of the 'patches' on the membrane surface is seen [43]. Without additives, many small patches can be observed in Figure 9a, while adding TEA+SDS results in larger patches which can be regarded as larger ridges (Figure 9b).
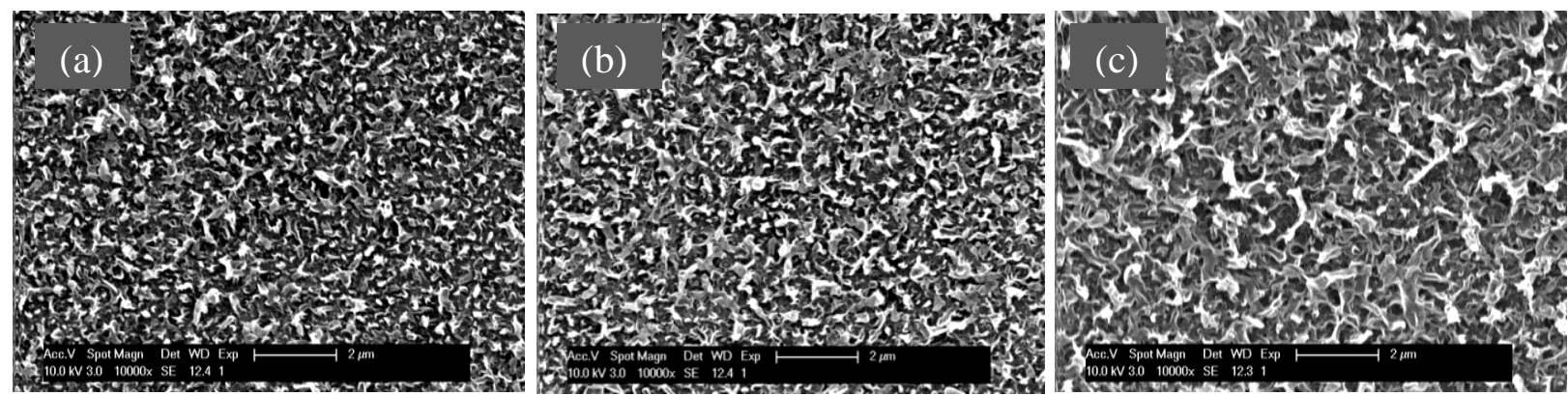

Figure 8: SEM surface images of TFC membranes synthesized with (a) only MPD, (b) MPD and TEA and (c) MPD, TEA and SDS in the aqueous phase.

(a)

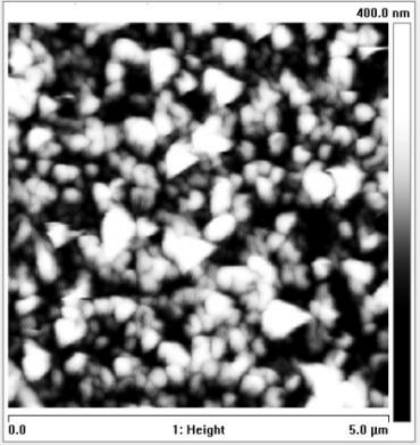

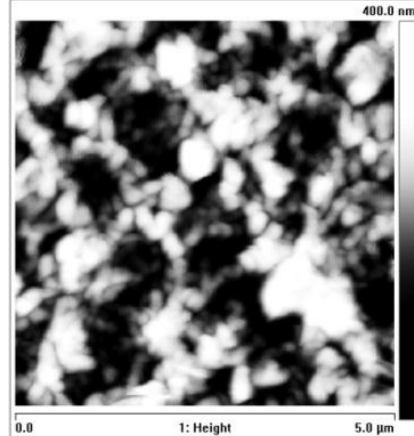

(b)

Figure 9: AFM images of water immersed TFC membranes, synthesized with (a) only MPD and (b) MPD, TEA and SDS in the aqueous phase.

\subsection{Curing temperature}

In order to study the effect of curing, the TFC membranes were dried overnight and then placed in an oven for 10 minutes at various temperatures between $25^{\circ} \mathrm{C}$ and $110^{\circ} \mathrm{C}$. Figure 
10a shows that the permeance decreased with increasing curing temperature, whereas the salt rejection increased from $92 \%$ to $97.5 \%$ when the temperature was elevated from $25^{\circ} \mathrm{C}$ to $50^{\circ} \mathrm{C}$. A further increase in curing temperature had a negligible effect on the salt rejection.

(a)
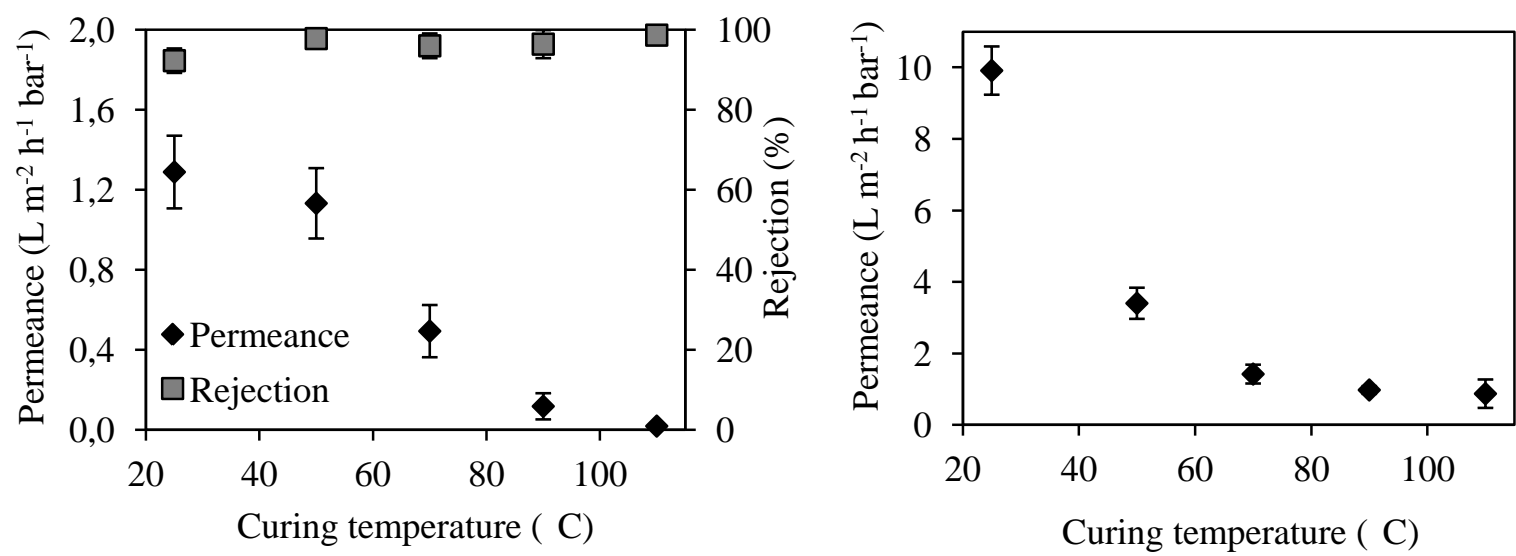

Figure 10: (a) Water permeance and salt rejection of TFC membranes cured at various temperatures for $10 \mathrm{~min}$. Synthesis conditions: MPD, TEA and SDS present in the aqueous solution, $18 \%$ PSf in casting solution of the support and 60 s reaction time. Filtration conditions: 49 bar, $1 \mathrm{~g} / \mathrm{L} \mathrm{MgSO}_{4}$. (b) Water permeance of heat treated PSf support layers. Filtrations carried out at 20 bar.

The surface charge measured using zeta potential was similar for all cured temperatures (Figure E in SI), which indicates that curing had a minor impact on surface chemistry in this study. ATR-FTIR results confirm this finding (Figure F in SI). It is noted that techniques with higher surface sensitivity (ATR equipped with a crystal with higher refractive index or XPS) previously indicated that changes in the surface chemistry can occur following curing [13].

The thickness of the PA layer cured at $25^{\circ} \mathrm{C}$, estimated from the TEM images (Figure 11), was $210 \pm 87 \mathrm{~nm}$, which is thicker than that of the membranes cured at $50^{\circ} \mathrm{C}$ and $110^{\circ} \mathrm{C}(152$ $\pm 53 \mathrm{~nm}$ and $179 \pm 49 \mathrm{~nm}$, respectively). Prior to the curing, all membranes had a similar thickness (similar to the membrane cured at $25^{\circ} \mathrm{C}$ ). Therefore, the thinner layer following curing can imply the more dense structure is due to additional cross-linking of initially unreacted chains [44]. In addition, the PA layer might contain a lot of H-bonded water after the synthesis which gets removed at the higher curing temperatures, hence de-swelling the PA layer and decreasing its thickness. The standard deviation on the thickness of the membrane cured at $25^{\circ} \mathrm{C}$ is higher compared to the membranes cured at $50^{\circ} \mathrm{C}$ and $110^{\circ} \mathrm{C}$. This can be attributed to less variation in the ridge and valley topography when a higher curing temperature is applied. This different topography can also be seen by the SEM images of the PA surface, which show that the membrane cured at $110^{\circ} \mathrm{C}$ has a less pronounced ridge and valley topography (Figure 11f). Furthermore, AFM images taken from the swollen surface (Figure 12) and the corresponding surface roughness $\left(\mathrm{R}_{\mathrm{q}} 117 \pm 28 \mathrm{~nm}\right.$ and $74 \pm 8 \mathrm{~nm}$ for membranes cured at $25^{\circ} \mathrm{C}$ and $110^{\circ} \mathrm{C}$, respectively) show the same trend. This observation in swollen state thus confirms that chemical changes have indeed taken place during the curing. The densified, cross-linked polymer packing can explain the moderate decrease in the permeance after curing at 25 and $50^{\circ} \mathrm{C}$ [15]. Moreover, the thick active layer together with 
the relatively high intrinsic permeance when curing at $25^{\circ} \mathrm{C}$, can also result in a higher concentration polarization [45], which can explain the lower rejection at low curing temperature. However, the changes in morphology of the membranes cured at $50^{\circ} \mathrm{C}$ and $110^{\circ} \mathrm{C}$ are not very obvious, and do not seem to explain the significant difference in permeance between these membranes $\left(1.13\right.$ and $0.02 \mathrm{~L} \mathrm{~m}^{-2} \mathrm{~h}^{-1} \mathrm{bar}^{-1}$ for $50^{\circ} \mathrm{C}$ and $110^{\circ} \mathrm{C}$, respectively).

(a)

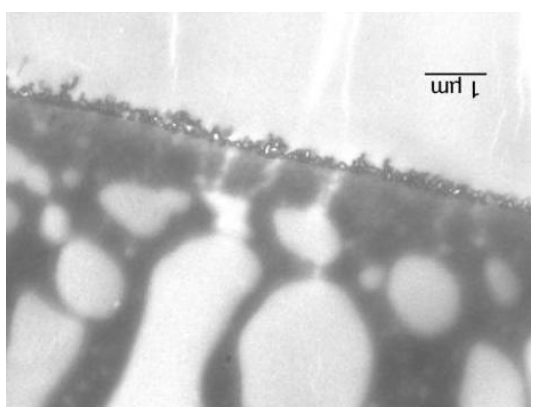

(c)

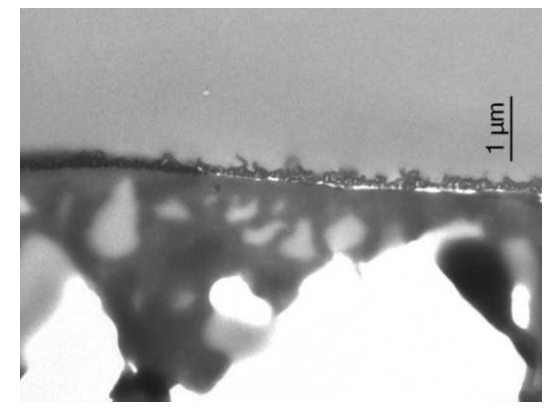

(e)

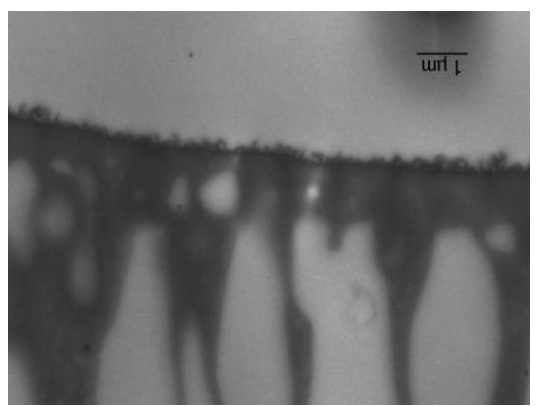

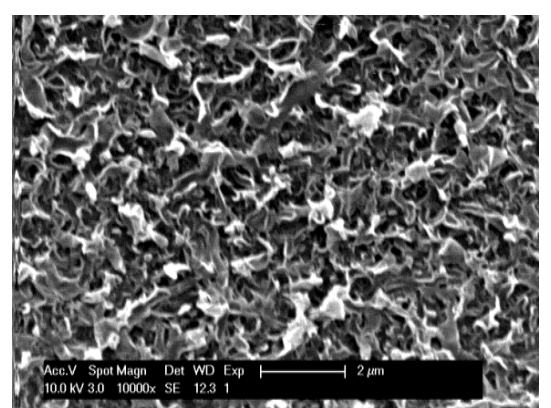

(b)

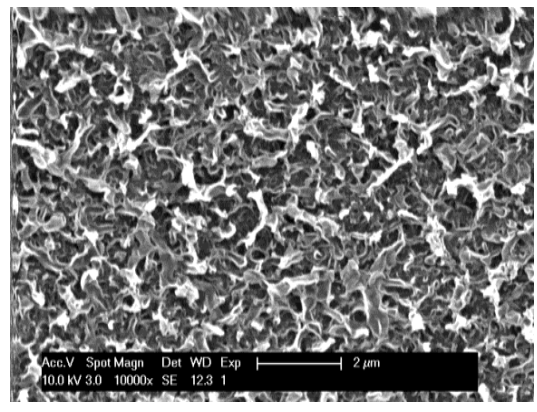

(d)

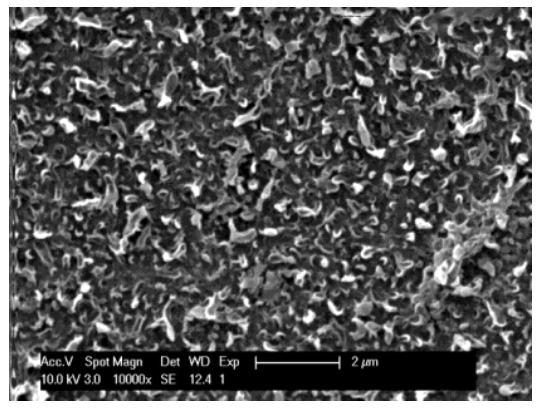

(f)

Figure 11: TEM cross-section images (left) and SEM surface images (right) of TFC membranes cured at $25^{\circ} \mathrm{C}$ $(\mathrm{a}, \mathrm{b}), 50^{\circ} \mathrm{C}(\mathrm{c}, \mathrm{d})$ and $110^{\circ} \mathrm{C}(\mathrm{e}, \mathrm{f})$. 
(a)

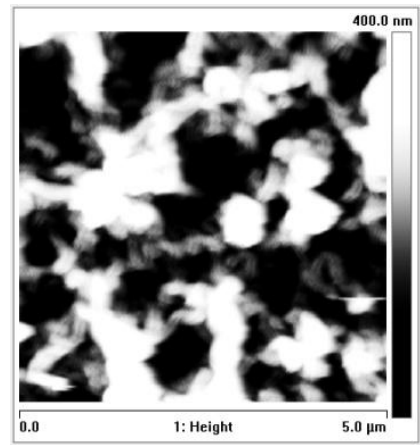

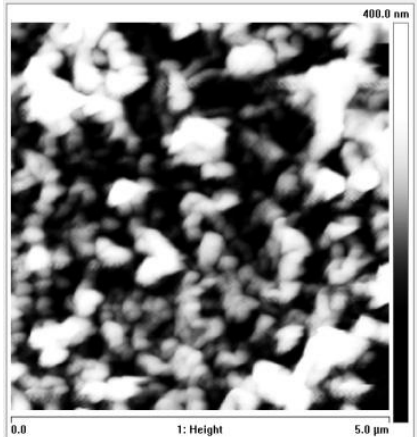

(b)

Figure 12: AFM images of water immersed TFC membranes, cured at (a) $25^{\circ} \mathrm{C}$ and (b) $110^{\circ} \mathrm{C}$.

Therefore, the effect of curing was also investigated on the level of the support membrane. Previous studies as well as this one, showed the important role of the support membrane structure on the formation and performance of TFC membranes [16-19]. Nevertheless, the influence of a heat treatment on the PSf support layer performance has usually been disregarded. To study this effect, a distinction was made between the uncoated PSf support and the TFC membrane. Similar as for the TFCs, the uncoated supports were dried overnight before placing them 10 minutes in an oven at various temperatures between $25^{\circ} \mathrm{C}$ and $110^{\circ} \mathrm{C}$. The permeance of the uncoated PSf supports is presented in Figure 10b. Even though the absence of a top layer will surely have biased the performance of the supports, an indication of the effect of heat treatment on the support was still obtained.

From Figure $10 \mathrm{~b}$, a strong flux decline between $25^{\circ} \mathrm{C}$ and $50^{\circ} \mathrm{C}$ (10 to $3.5 \mathrm{~L} \mathrm{~m}^{-2} \mathrm{~h}^{-1} \mathrm{bar}^{-1}$, respectively) was observed for the heat treated PSf supports, while this trend was less obvious for the TFC membranes. The permeance decrease of the uncoated PSf membranes after the heat treatment is most likely caused by pore collapse due to capillary forces during the drying process [46]. The more similar permeance of the PA TFC membranes cured at $25^{\circ} \mathrm{C}$ and $50^{\circ} \mathrm{C}$ can imply that the presence of a PA top layer might prevent the pores at the top surface of the support layer from collapsing at $50^{\circ} \mathrm{C}$ curing. Moreover, even if the pores in the PSf support membrane were (partially) collapsed, the dense PA top layer should still determine the membrane performance, considering the much lower permeances of the coated PSf. It can be concluded that for TFC membranes, the largest effect of the curing temperature is presumably situated in the PA top layer, since otherwise a strong permeance decrease between $25^{\circ} \mathrm{C}$ and $50^{\circ} \mathrm{C}$ should have been detected for the TFCs as well. This confirms that densification of the PA layer occurs at higher temperatures, as stated earlier. Additionally to the removal of excess organic solvent and sorbed water, further cross-linking of the PA top layer thus occurs during the drying process $[14,47]$. 
(a)

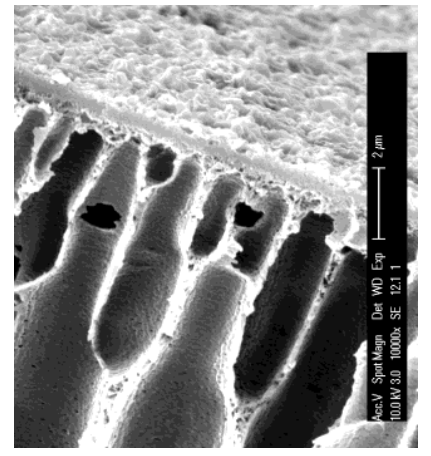

(b)

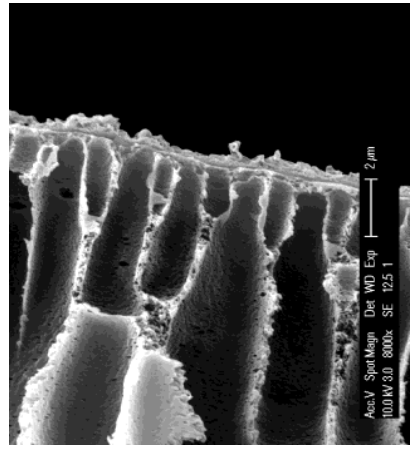

(c)

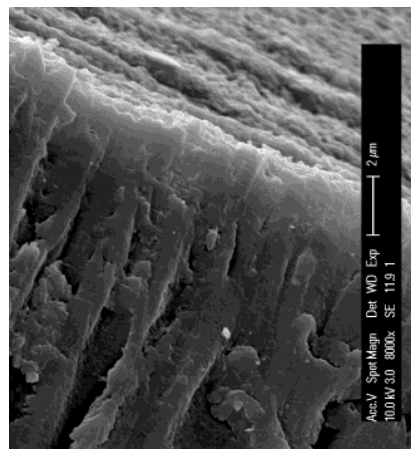

Figure 13: SEM cross-section images of TFC membranes: (a) cured at $50^{\circ} \mathrm{C}$, (b and c) cured at $110^{\circ} \mathrm{C}$.

Heat treatment of uncoated PSf and TFC membranes at temperatures higher than $50^{\circ} \mathrm{C}$, resulted in a significant decrease of the permeance for both membrane types. The very low permeance of the high temperature treated PSf membranes $\left(1.1 \pm 0.2 \mathrm{~L} \mathrm{~m}^{-2} \mathrm{~h}^{-1} \mathrm{bar}^{-1}\right.$ for temperatures above $50^{\circ} \mathrm{C}$ ) is in the same order of magnitude as for TFC membranes cured at only $25^{\circ} \mathrm{C}$. Therefore, the low permeance of the cured TFC membranes at temperatures higher than $50^{\circ} \mathrm{C}$ is also the result of pore collapse in the PSf support, together with densification of the top layer at high temperatures. The SEM images of the cross-sections of TFC membranes cured at $50^{\circ} \mathrm{C}$ and $110^{\circ} \mathrm{C}$ in Figure 13 show a clear change in morphology. For the latter, collapsed macrovoids in the skin of the PSf support were visible at several spots (Figure 13c), as also seen by others [48]. TEM images taken of membranes cured at $110^{\circ} \mathrm{C}$ (Figure 11e) also reveal that the interface between the PSf support and PA layer was difficult to detect, which could indicate the formation of an interpenetrating network between the two polymers, as was also suggested by Song et al. [49]. It is noted that, although curing can be detrimental to the membrane permeance, it is necessary to induce conformational (e.g. hydrogen bonding) and chemical (e.g. intermolecular cross-linking) changes in the top layer to achieve high selectivity [48]. From our experiments, it seems that curing at a mild temperature $\left(50^{\circ} \mathrm{C}\right)$ makes it possible to obtain the desired properties.

\section{Conclusions}

The effect of various parameters during PA formation was systematically investigated. The performance of the resulting TFC membranes was measured using a high throughput filtration set-up and the results were correlated to the PA active layer structure measured using SEM, TEM and (water immersed) AFM. In addition, for some conditions, the TFC membranes were analyzed using ATR-FTIR spectroscopy and zeta potential measurements.

It was found that the porous support has an optimum porosity factor in order to prepare a TFC membrane with high performance. This performance was obtained already after $15 \mathrm{~s}$ of the PA polymerization, indicating that the incipient active layer, based on the accepted duallayer PA model, is completed already within this relatively short time. Prolonging the reaction time mainly resulted in an increase in the overall active layer thickness and change in morphology, as revealed by TEM and SEM. The addition of a surfactant (SDS) together with a base (TEA) was necessary to obtain a high performance, whereas adding each 
separately did not improve the performance. This was explained by the effect the additives have on the formation of the incipient layer or due to defects in the PA layer which might occur during its formation. This correlated well with the membrane performance, thickness and morphology. Curing at $50^{\circ} \mathrm{C}$ was found to be essential to obtain a high performance due to extra cross-linking of the active layer. However, curing at higher temperatures reduced the permeance significantly. The latter was associated with the effect of the curing on the support membrane. It was demonstrated that the TFC membrane performance and PA morphology did change significantly by altering synthesis parameters, as reflected in SEM, AFM and TEM; whereas only minor changes in the physicochemical characteristics of the membranes were detected by zeta potential and ATR-FTIR spectroscopy when the same synthesis parameters were varied.

\section{Acknowledgements}

This work has been performed in the frame of the IAP 6/27 Functional Supramolecular Systems of the Belgian Federal Government. The authors are grateful to KU Leuven for support under the Methusalem grant CASAS and OT/11/061. Also, we wish to thank the Laboratory for Entomology of KU Leuven for chemicals and procedures for TEM and A. Mamoutov (Ben-Gurion university) for her assistance with the zeta potential measurements.

\section{References}

[1] R.J. Petersen, Composite reverse osmosis and nanofiltration membranes, J. Membr. Sci., 83 (1993) 81-150.

[2] E. Cadotte John, Evolution of Composite Reverse Osmosis Membranes, in: Materials Science of Synthetic Membranes, American Chemical Society, 1985, pp. 273-294.

[3] K.P. Lee, T.C. Arnot, D. Mattia, A review of reverse osmosis membrane materials for desalination-Development to date and future potential, J. Membr. Sci., 370 (2011) 1-22.

[4] W.J. Lau, A.F. Ismail, N. Misdan, M.A. Kassim, A recent progress in thin film composite membrane: A review, Desalination, 287 (2012) 190-199.

[5] S. Qiu, L. Wu, L. Zhang, H. Chen, C. Gao, Preparation of reverse osmosis composite membrane with high flux by interfacial polymerization of MPD and TMC, J. Appl. Polym. Sci., 112 (2009) 2066-2072.

[6] B. Tang, C. Zou, P. Wu, Study on a novel polyester composite nanofiltration membrane by interfacial polymerization. II. The role of lithium bromide in the performance and formation of composite membrane, J. Membr. Sci., 365 (2010) 276-285.

[7] M. Duan, Z. Wang, J. Xu, J. Wang, S. Wang, Influence of hexamethyl phosphoramide on polyamide composite reverse osmosis membrane performance, Sep. Purif. Technol., 75 (2010) 145155 .

[8] Y. Mansourpanah, K. Alizadeh, S.S. Madaeni, A. Rahimpour, H. Soltani Afarani, Using different surfactants for changing the properties of poly(piperazineamide) TFC nanofiltration membranes, Desalination, 271 (2011) 169-177. 
[9] S.-Y. Kwak, S.G. Jung, S.H. Kim, Structure-Motion-Performance Relationship of Flux-Enhanced Reverse Osmosis (RO) Membranes Composed of Aromatic Polyamide Thin Films, Environ. Sci. Technol., 35 (2001) 4334-4340.

[10] S.-H. Chen, D.-J. Chang, R.-M. Liou, C.-S. Hsu, S.-S. Lin, Preparation and separation properties of polyamide nanofiltration membrane, J. Appl. Polym. Sci., 83 (2002) 1112-1118.

[11] B.J.A. Tarboush, D. Rana, T. Matsuura, H.A. Arafat, R.M. Narbaitz, Preparation of thin-filmcomposite polyamide membranes for desalination using novel hydrophilic surface modifying macromolecules, J. Membr. Sci., 325 (2008) 166-175.

[12] A.K. Ghosh, B.-H. Jeong, X. Huang, E.M.V. Hoek, Impacts of reaction and curing conditions on polyamide composite reverse osmosis membrane properties, J. Membr. Sci., 311 (2008) 34-45.

[13] A. Prakash Rao, S.V. Joshi, J.J. Trivedi, C.V. Devmurari, V.J. Shah, Structure-performance correlation of polyamide thin film composite membranes: effect of coating conditions on film formation, J. Membr. Sci., 211 (2003) 13-24.

[14] A. Soroush, J. Barzin, M. Barikani, M. Fathizadeh, Interfacially polymerized polyamide thin film composite membranes: Preparation, characterization and performance evaluation, Desalination, 287 (2012) 310-316.

[15] A. Prakash Rao, N.V. Desai, R. Rangarajan, Interfacially synthesized thin film composite RO membranes for seawater desalination, J. Membr. Sci., 124 (1997) 263-272.

[16] A. Sotto, A. Rashed, R.-X. Zhang, A. Martínez, L. Braken, P. Luis, B. Van der Bruggen, Improved membrane structures for seawater desalination by studying the influence of sublayers, Desalination, 287 (2012) 317-325.

[17] P.S. Singh, S.V. Joshi, J.J. Trivedi, C.V. Devmurari, A.P. Rao, P.K. Ghosh, Probing the structural variations of thin film composite RO membranes obtained by coating polyamide over polysulfone membranes of different pore dimensions, J. Membr. Sci., 278 (2006) 19-25.

[18] G.Z. Ramon, M.C.Y. Wong, E.M.V. Hoek, Transport through composite membrane, part 1: Is there an optimal support membrane?, J. Membr. Sci., 415-416 (2012) 298-305.

[19] A.K. Ghosh, E.M.V. Hoek, Impacts of support membrane structure and chemistry on polyamidepolysulfone interfacial composite membranes, J. Membr. Sci., 336 (2009) 140-148.

[20] G.Z. Ramon, E.M.V. Hoek, Transport through composite membranes, part 2: Impacts of roughness on permeability and fouling, J. Membr. Sci., 425-426 (2013) 141-148.

[21] E.M. Vrijenhoek, S. Hong, M. Elimelech, Influence of membrane surface properties on initial rate of colloidal fouling of reverse osmosis and nanofiltration membranes, J. Membr. Sci., 188 (2001) $115-128$.

[22] P. Vandezande, L.E.M. Gevers, J.S. Paul, I.F.J. Vankelecom, P.A. Jacobs, High throughput screening for rapid development of membranes and membrane processes, J. Membr. Sci., 250 (2005) 305-310.

[23] High-Throughput Membrane Systems Leuven, www.html-membrane.be (2014). 
[24] D.G. Cahill, V. Freger, S.-Y. Kwak, Microscopy and Microanalysis of Reverse-Osmosis and Nanofiltration Membranes, MRS Bulletin, 33 (2008) 27-32.

[25] V. Freger, Nanoscale Heterogeneity of Polyamide Membranes Formed by Interfacial Polymerization, Langmuir, 19 (2003) 4791-4797.

[26] V. Freger, Kinetics of Film Formation by Interfacial Polycondensation, Langmuir, 21 (2005) 1884-1894.

[27] A. Cano-Odena, M. Spilliers, T. Dedroog, K. De Grave, J. Ramon, I.F.J. Vankelecom, Optimization of cellulose acetate nanofiltration membranes for micropollutant removal via genetic algorithms and high throughput experimentation, J. Membr. Sci., 366 (2011) 25-32.

[28] Y.H. See-Toh, F.C. Ferreira, A.G. Livingston, The influence of membrane formation parameters on the functional performance of organic solvent nanofiltration membranes, J. Membr. Sci., 299 (2007) 236-250.

[29] P. Vandezande, X. Li, L.E.M. Gevers, I.F.J. Vankelecom, High throughput study of phase inversion parameters for polyimide-based SRNF membranes, J. Membr. Sci., 330 (2009) 307-318.

[30] K. Boussu, C. Vandecasteele, B. Van der Bruggen, Study of the characteristics and the performance of self-made nanoporous polyethersulfone membranes, Polymer, 47 (2006) 3464-3476.

[31] M. Dalwani, N.E. Benes, G. Bargeman, D. Stamatialis, M. Wessling, Effect of pH on the performance of polyamide/polyacrylonitrile based thin film composite membranes, J. Membr. Sci., 372 (2011) 228-238.

[32] V. Freger, Swelling and Morphology of the Skin Layer of Polyamide Composite Membranes: An Atomic Force Microscopy Study, Environ. Sci. Technol., 38 (2004) 3168-3175.

[33] S.-Y. Kwak, D. Woo Ihm, Use of atomic force microscopy and solid-state NMR spectroscopy to characterize structure-property-performance correlation in high-flux reverse osmosis (RO) membranes, J. Membr. Sci., 158 (1999) 143-153.

[34] J. Xiang, Z. Xie, M. Hoang, K. Zhang, Effect of amine salt surfactants on the performance of thin film composite poly(piperazine-amide) nanofiltration membranes, Desalination, 315 (2013) 156-163.

[35] J.E. Tomaschke, Interfacially synthesized reverse osmosis membrane containing an amine salt and processes for preparing the same, US Patent 4,872,984 (1989).

[36] F.A. Carey, R.J. Sundberg, Advanced organic chemistry. Part A: Structure and mechanisms, 5th ed., Springer US, 2007.

[37] J.E. Cadotte, Interfacially synthesized reverse osmosis membrane, US Patent 4,277,344 (1981).

[38] C. Hansch, A. Leo, D.H. Hoekman, Exploring QSAR - hydrophobic, electronic, and steric constants, American Chemical Society, Washington, DC, 1995.

[39] S.A. Sundet, Morphology of the rejecting surface of aromatic polyamide membranes for desalination, J. Membr. Sci., 76 (1993) 175-183.

[40] R. Nadler, S. Srebnik, Molecular simulation of polyamide synthesis by interfacial polymerization, J. Membr. Sci., 315 (2008) 100-105. 
[41] Y. Mansourpanah, S.S. Madaeni, A. Rahimpour, Fabrication and development of interfacial polymerized thin-film composite nanofiltration membrane using different surfactants in organic phase; study of morphology and performance, J. Membr. Sci., 343 (2009) 219-228.

[42] E.L. Wittbecker, P.W. Morgan, Interfacial polycondensation. I, J. Polym. Sci., 40 (1959) 289297.

[43] R. Bernstein, S. Belfer, V. Freger, Surface Modification of Dense Membranes Using Radical Graft Polymerization Enhanced by Monomer Filtration, Langmuir, 26 (2010) 12358-12365.

[44] G.-Y. Chai, W.B. Krantz, Formation and characterization of polyamide membranes via interfacial polymerization, J. Membr. Sci., 93 (1994) 175-192.

[45] E.M.V. Hoek, M. Elimelech, Cake-enhanced concentration polarization: a new fouling mechanism for salt-rejecting membranes, Environ. Sci. Technol., 37 (2003) 5581-5588.

[46] I. Pinnau, B.D. Freeman, Formation and Modification of Polymeric Membranes: Overview, in: Membrane Formation and Modification, American Chemical Society, 1999, pp. 1-22.

[47] N.K. Saha, S.V. Joshi, Performance evaluation of thin film composite polyamide nanofiltration membrane with variation in monomer type, J. Membr. Sci., 342 (2009) 60-69.

[48] C.R. Bartels, K.L. Kreuz, A. Wachtel, Structure-performance relationships of composite membranes: Porous support densification, J. Membr. Sci., 32 (1987) 291-312.

[49] Y. Song, P. Sun, L.L. Henry, B. Sun, Mechanisms of structure and performance controlled thin film composite membrane formation via interfacial polymerization process, J. Membr. Sci., 251 (2005) 67-79. 


\section{Supplementary Information}

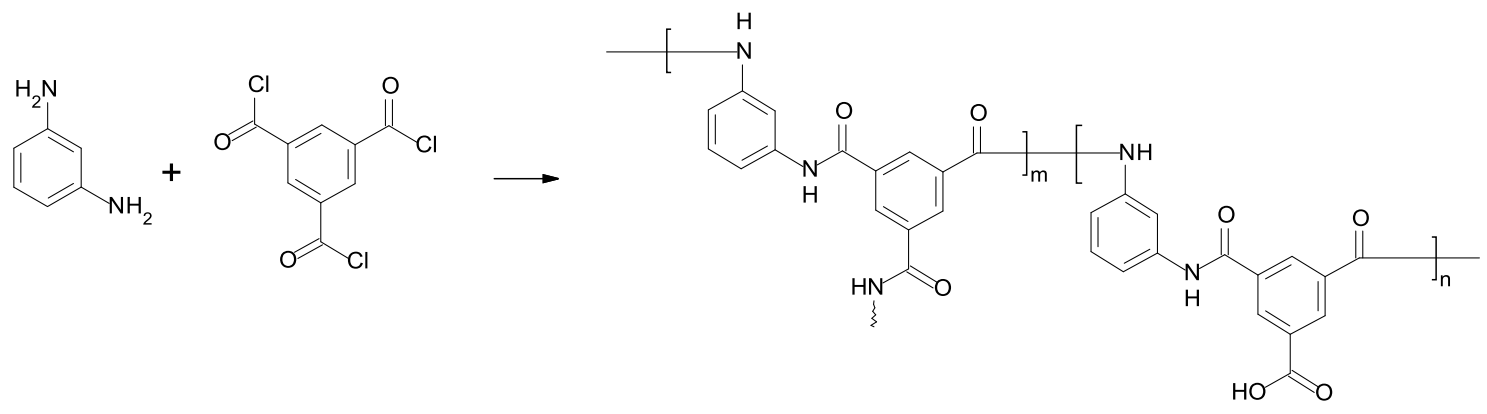

Figure A: Chemical structures of MPD, TMC and the product of polymerization PA. The COOH-group in the PA structure represents a possible non-polymerized but hydrolyzed acyl group.

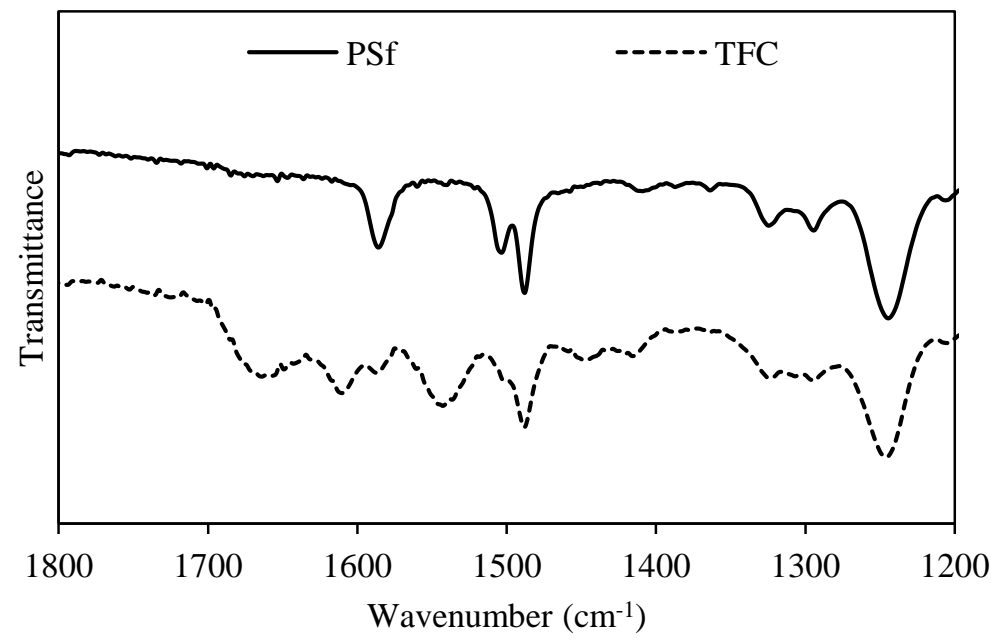

Figure B: ATR-IR spectra of a PSf support layer (full line) and a TFC membrane with a PA top layer (dashed line).

The polymerization was verified using ATR-FTIR spectroscopy. Figure B shows the ATR-IR spectra of a PSf support layer and a TFC membrane. The two new characteristic peaks of the aromatic PA - at $1670 \mathrm{~cm}^{-1}$ and $1540 \mathrm{~cm}^{-1}$ assigned to $\mathrm{C}=\mathrm{O}$ and $\mathrm{C}-\mathrm{N}$ stretch, respectively - are clearly seen in the spectrum of the TFC membrane. 


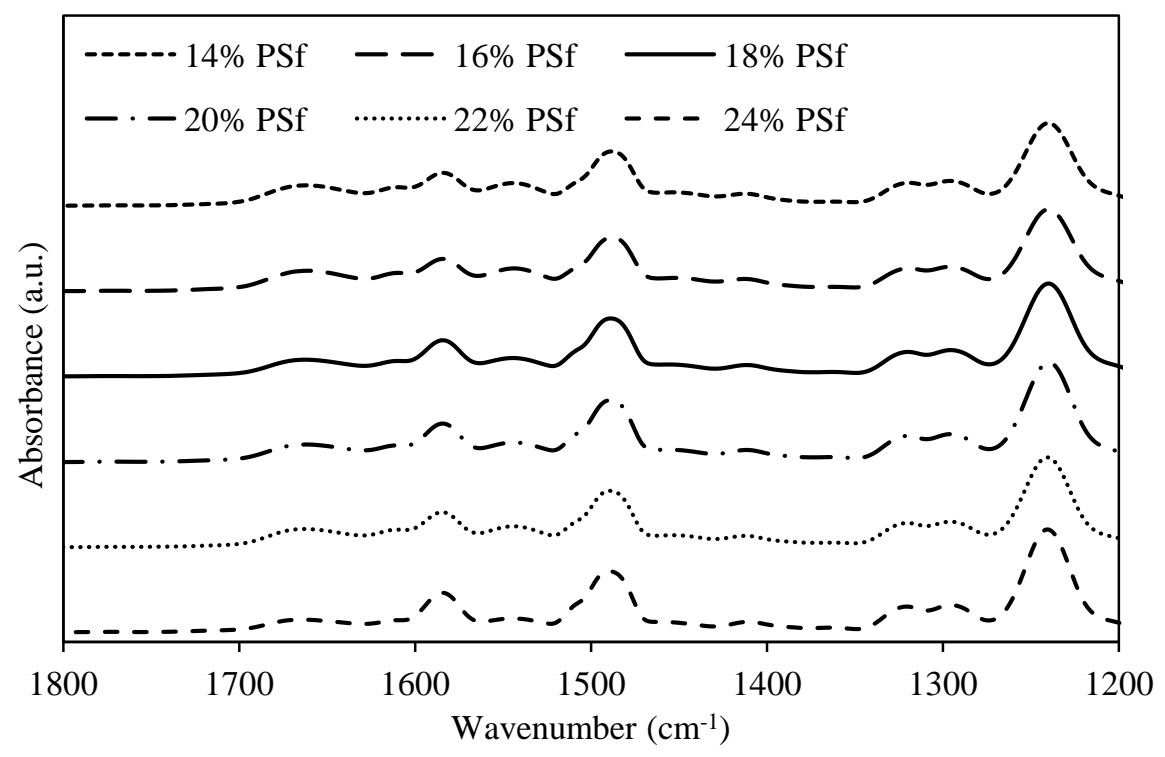

Figure C: ATR-FTIR spectra of TFC PA membranes synthesized on supports cast from various PSf concentrations. Synthesis conditions: MPD, TEA and SDS present in the aqueous solution, $60 \mathrm{~s}$ reaction time and curing at $50^{\circ} \mathrm{C}$ for $10 \mathrm{~min}$.

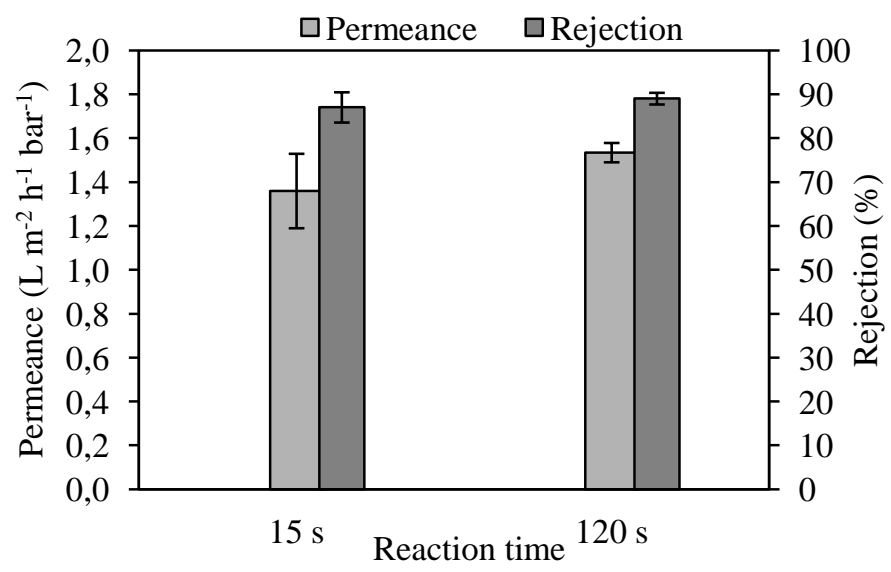

Figure D: Water permeance and salt rejection of TFC membranes synthesized without TEA, with $15 \mathrm{~s}$ and 120 $\mathrm{s}$ reaction time. Synthesis conditions: MPD and SDS present in the aqueous solution, $18 \%$ PSf in casting solution of the support and curing at $50^{\circ} \mathrm{C}$ for $10 \mathrm{~min}$. Filtration conditions: $20 \mathrm{bar}, 1 \mathrm{~g} / \mathrm{L} \mathrm{MgSO}_{4}$. 


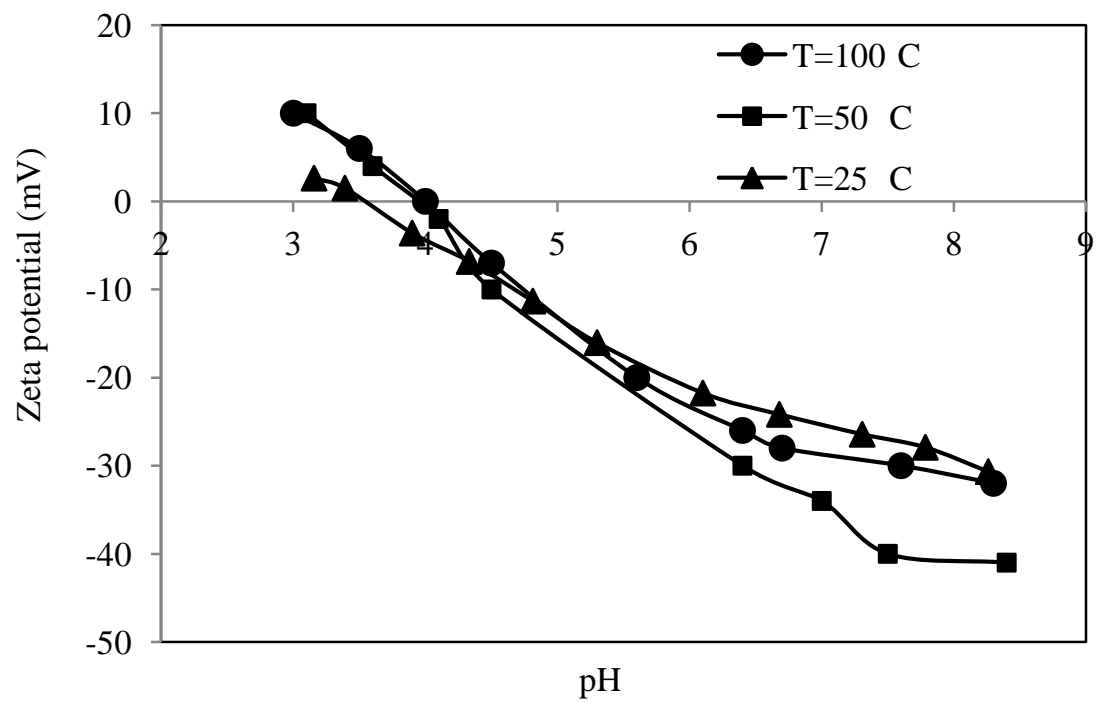

Figure E: Zeta potential of TFC membranes cured at $25^{\circ} \mathrm{C}, 50{ }^{\circ} \mathrm{C}$ and $100{ }^{\circ} \mathrm{C}$. Measuring conditions: $10 \mathrm{mM}$ $\mathrm{KCl}$.

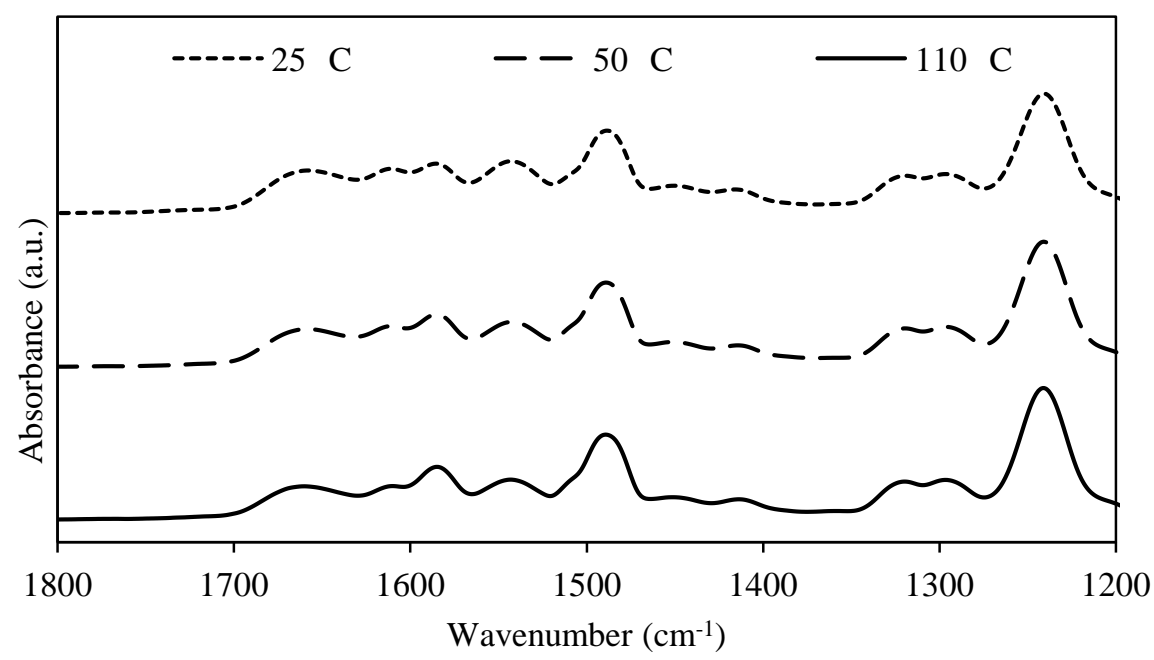

Figure F: ATR-FTIR spectra of TFC membranes cured at various temperatures for 10 min. Synthesis conditions: MPD, TEA and SDS present in the aqueous solution, 18\% PSf in casting solution of the support and $60 \mathrm{~s}$ reaction time. 